and borborygmi within half an hour and I am inclined to think the purity of the air breathed by the dyspeptic quite as important as his regimen or his teeth. It must, I think, sooner or later be recognised that many of the increasing ills which it has been the fashion to charge on the "hurry and brain fag" incidental to a high state of civilisation and a large population are in reality due to the greater contamination of the air we breathe by the waste products of that -population, and that toxins excreted by the lungs will in time take high rank among these as both potent and insidious. If this should come to pass the present ideas anent ventilation must be abandoned as utterly futile, and the need will be felt, not of letting a little air in, but of rushing waste products out, a vastly different matter, for , which the Tobin's tube and tiny so-called rentilator are hopelessly inadequate. Our methods of ventilation generally - must be more approximated to those now approved by the Colleges for the airing of the phthisical patient; and, above ,all things, we must sleep in a "thorough draught" of pure air. The "surface ventilator" for sewers-that cheap and effective fouler of our street air-must surely also go.

It would seem that any departure from health is more and more to be recognised as due to some definite cause-mostly to some definite poison-which poison (or its producer) has most commonly been introduced from without; in fact, .with some very obvious qualification and reservation, a paraphrase of the first law of motion might almost stand as a first law of medicine-viz., the body in health will continue in health unless acted on by some external poison. Whether or no any fresh grain of truth may have been turned up by my ignorant groping, of this I am certain, that the subject of re-breathed air in its relation to disease affords a grand field for skilled and accurate scientific research.

Darlington.

\section{A CASE OF I_ARGE CYSTIC ABDOMINAL TUMOUR PROBABLY OF THE BROAD LIGAMENT OR OVARY OF UNUSUAL DURATION AND SLOW GROWTH.}

- BY J. DAUBER, M.A., M.B., B.CH. OxON., M.R.C.P. LOND.,

ASSISTANT PHYSICIAN TO THE HOSPITAL FOR WOMEN, SOHO.

I AM not acquainted with any recorded case of ovarian or broad ligament cyst of large size with a history of over fifty years' duration, and as the following case appears to me to be authentic and genuine it may be of some interest to place it on record.

I saw the patient on two separate occasions in my outpatient department at the Hospital for Women, Soho, with an interval of several months between them-the second time being in February, 1897. On both occasions careful notes of her statements were taken and she was subjected to a somewhat severe cross-examination. She was frank, candid, and intelligent, and made no statements of a contradictory and inconsistent character. She gave her age as seventy years, and was a thin, small, and shrunken woman. Her leanness was less noticeable when she was dressed, because of the distension of the abdomen; moreover, she wore a large amount of padding over the chest, as she explained, "to correspond with her stomach." Upon examination the abdomen was scen to be completely occupied by a large tumour extending from the pubes to the ensiform cartilage and bulging on either side as she lay on her back beyond her body. The tumour was not very tense; it was uniformly dull on perçussion; the flanks were resonant and the area of dulness was not altered by change of position. Fluctuation was easily obtainable wherever the dulness extended. The girth at the umbilicus was 43 in. Per vaginam, senile atrophic changes were well marked. The uterus was small, low, and moveable.

The history she gave was that as a girl as far back as she could remember she was always " high-stomached," but that at fourteen or fifteen years of age this became so noticeable that people commented upon it, so much so, indeed, that her father - her mother being confined to bed at the time-took her with him to consult Mr. Cumplin of Charterhouse-street, who after examining the abdomen called her father aside and informed him that he considered she was pregnant. Her father was doubtful and said: "Well, be that as it may, she shall not leave my roof till it is over." The tumour continued to increase if at all very slowly, and at the end of about ten months her father took her to see Mr. Cumplin again, who then admitted he had been in error and advised the patient to consult Dr. Frederick Bird of Brook-street. Her mother took her to him and the patient was very positive that she was not more than fifteen years of age-certainly not more than sixteen-at the time of this visit. Dr. Bird pronounced the swelling to be due to an ovarian tumour. He seems to have taken much interest in the case and the patient speaks most gratefully of his kindness throughout a long series of years. She invariably declined all operative measures, even tapping, when suggested to her, though from time to time Dr. Bird and Sir Spencer Wells, who saw her with him on more than one occasion, pressed her to undergo operation. For a time she was in Dr. Bird's private hospital in Carey-street, Lincoln's Inn, which, according to the patient's statement, he carried on with five other medical men " each having one bed and paying the cost of it."

The patient was twice married, first in 1843 , when she says she was nineteen or twenty years of age-but either age would make her over seventy years old now. Her first husband died when she was six months pregnant with her first child, about two years after marriage. She was married again in 1849, and this time to Dr. Bird's coachman, and so remained under Dr. Bird's observation for many years. She had four children, one-which was posthumous--by her first husband; three by her second. The first child was a boy ; it was a "crossbirth" and stillborn. Dr. Jameson of Finsbury-pavement attended her. The second child (a girl) was born in 1850 ; this was also a "crossbirth" and stillborn. A "gentleman from South Audley-street," whose name she cannot recall, attended her with this child. At the third confinement Dr. Bird and Dr. Merriman of Grosvenor-street were present and they succeeded in delivering her of a live child (a girl) who lived to the age of thirty-two years. Dr. Bird, with his friend Dr. Morgan, again assisted her at the birth of the fourth child (a boy) who survived to his fourth year. All the labours were very difficult.

I think from these detailed statements, which to me bear the impress of veracity, there can be but little doubt that her present large tumour was also of considerable size at the age of fifteen years, that it subsequently complicated all her confinements and that it excited much interest in the minds of Dr. Bird, Sir Spencer Wells and some other gynæcologists at a time when ovariotomy had not become an established operation, but when the treatment by tapping was gradually being abandoned in favour of the radical cure. I may add that the patient declines all operative treatment at the present time as persistently as she has done all her life.

Charles-street, Berkeley-square, $\mathbf{W}$.

\section{A CASE OF LAPARO-NEPHRECTOMY IN AN INFANT SIXTEEN MONTHS OLD.}

\section{By J. A. CAMPBELL KYNOCH, M.B., C.M. EdIN.}

THE question of operative treatment in cases of malignant tumours of the kidney in young children is one on which there is still difference of opinion. The operation has not received much favour in this country. Thus Bland Sutton states that nephrectomy in such cases is absolutely unavailing (1) on account of the frequent immediate fatal results and (2) the almost certain early recurrence of the disease in those cases that recover from the operation. He tabulates 21 cases of operation for renal sarcoma in children under six years of age with the following results : 12 died from the operation, and of the 9 that recovered all died from recurrence within one year. The late Mr. Greig Smith held that the operation was only justifiable (1) if the tumour was small ; (2) if the general condition of the patient was satisfactory; and (3) if the patient was at least four years of age. Keith states that in young children it is doubtful whether it is ever right to operate. In Germany the operation is much more frequently undertaken, except in those cases in which 